\title{
A RELAÇÃO PROFESSOR-ALUNO VISTA PELA ÓTICA CINEMATOGRÁFICA
}

\section{Teruo Monobe}

\section{RESUMO}

O professor deve possuir o domínio do conteúdo, da comunicação e do relacionamento como elementos-chave para promover a aprendizagem. Desses, a relação professor-aluno constitui-se em um dos principais elementos, cujos outros componentes são: o respeito mútuo entre professor e aluno; a confiança que o aluno precisa ter no professor; o compromisso do aluno em seguir as instruções do professor; o interesse do professor com a aprendizagem do aluno; o acompanhamento e a reflexão sobre o progresso dos alunos por parte do professor. Essa relação incorpora, portanto, compromisso recíproco, evidenciando o conceito de confiança. A confiança é tão importante quanto perigosa, pois envolve o risco de que a pessoa em quem se deposita a confiança possa desapontar, ocasionando perdas e danos, incluindo de auto-estima. A relação de confiança obriga as partes a serem transparentes, para que não haja dúvida a respeito da boa-fé incorporada nessa relação. A avaliação que o professor conduz em testes subjetivos é na essência baseada na confiança; igualmente, o aluno não pode violar o princípio da confiança, trapaceando na prova. O filme "O Clube do Imperador” mostra a relação professor-aluno em sua plenitude, evidenciando como esses princípios podem ser válidos na prática.

\section{PALAVRAS-CHAVE}

Relação professor-aluno; Filmes educacionais; Filmes comerciais; Ética; Caráter; Confiança; Clube do Imperador.

\section{THE RELATIONSHIP BETWEEN TEACHER AND STUDENT UNDER THE CINEMATOGRAPHIC'S VIEW}

\begin{abstract}
The teacher ought to possess the control of the content, the communication and the relationship as the key elements of the learning process. Among these elements, the relationship between teacher and student becomes one of the main ones. Other elements are: the mutual respect of the teacher and the student; the trust that the student must have in his/her teacher; the student's commitment to following the instructions of the teacher; the teacher's interest on the student's learning; the follow-up and the careful examination of the progress of the student by the teacher. The relationship involves, therefore, a bond, evidencing the concept of trust. Trust is both important and dangerous, once it involves the risk of the person who trusts someone be disappointed, the risk of loss and damage, including self-esteem. The relationships based on trust requires that both parties be disclosed, so that there will be no doubts about the good faith involved in this relationship. The appraisal that the teacher conducts using subjective tests is essentially based on trust; on the other hand, the student cannot breach the principle of trust by cheating. "The Emperor's Club" shows the relationship between teacher and student, and that the principle of trust may also be valid in practice.
\end{abstract}

\section{KEYWORDS}

Movies; Relationships between teacher and student; Educational movies; Commercial movies; Ethics; Character; Trust; Emperor's Club. 


\section{INTRODUÇÃO}

A utilização de filmes em sala de aula, como apoio aos propósitos educacionais, tem provocado longas discussões por constituir-se em um poderoso veículo de comunicação, dependendo dos contextos em que são utilizados. Tornou-se prática comum o uso de trechos de filmes (de longa metragem) ou de filmes inteiros (quando documentários ou de curta metragem) como apoio pedagógico em programas de treinamento e desenvolvimento de pessoas, pelos paralelos que se podem traçar entre a narrativa do filme e determinadas situações nas áreas da liderança, motivação, coaching, avaliação, em setores do conhecimento de administração de empresas (como marketing, finanças, logística, etc), e até para fins de planejamento, organização, direção e coordenação de atividades empresariais.

É necessário ressaltar que os filmes do tipo documentário, geralmente de curta metragem, já têm sido utilizados como recurso pedagógico há muito tempo. Porém, os filmes ditos comerciais, de longa metragem, têm utilização mais recente. Em ambos os casos, tornase difícil precisar exatamente a eficácia dos seus resultados. Por se tratar muitas vezes de filmes de sucesso, protagonizados por atores conhecidos, com efeitos visuais especiais, cenas de ação que irradiam grande emoção e que se sobrepõem à realidade, os filmes comerciais inseridos em determinados contextos têm até maior utilização do que filmes de curta metragem, a não ser aqueles rodados para fins educacionais. A máxima do cinema é que não precisa ser real, mas verossímil.

Especificamente, em se tratando da relação entre professor e aluno, diversos filmes de longa metragem, que estiveram em cartaz no circuito nacional, já retrataram este tema, entre eles: “Adeus, Mr. Chips” (1939), “Ao Mestre, com Carinho” (1966), “A Sociedade dos Poetas Mortos” (1989), “Madadayo” (1992), “O Adorável Professor” (1995), “Mentes Perigosas” (1999), “O Sorriso de Monalisa” (2003), “Escritores da Liberdade” (2007), todos sob os mais diferentes ângulos, contextos e óticas culturais. Esses filmes, porém, seguramente não foram rodados tendo-se em mente a utilização do seu enredo com fins educacionais, muito embora hoje possam ser utilizados para ilustrar determinadas situações de desempenho da função de um professor. 
Embora haja alguma discussão a respeito da validade da utilização de filmes lançados nos circuitos comerciais para fins estritamente educacionais, embora de forma indireta, o que se pode verificar é que alguns estudos defendem seu uso por serem exemplos vívidos de situações cabíveis no contexto de uma discussão que envolve aspectos pedagógicos e andragógicos, em que uma determinada situação necessita de enredo, além dos recursos cinematográficos que incluem som, imagem e ação para reforçar os propósitos cognitivos estabelecidos.

Para que se possa verificar se os recursos cinematográficos são adequados para a aplicabilidade dos conceitos, a proposta deste estudo é analisar o filme "O Clube do Imperador” sob a ótica da relação professor-aluno. Trata-se de um filme comercial, de longa metragem (104 minutos), cujo enredo é propício para analisar as interações entre professor e aluno e que mostra aspectos educacionais em uma linguagem cinematográfica acessível ao grande público. O professor em questão, personagem central do filme, torna atitudes claras e posturas típicas de um verdadeiro educador.

\section{O CINEMA E OS FINS EDUCACIONAIS}

Alguns estudos, particularmente de Stillman II (2006), têm discutido a validade de se utilizarem filmes para fins educacionais. Em seu estudo, Stillman II (p.112-113) procura isentar-se de discutir as intenções dos cineastas quando rodam um filme; ele, a princípio, duvida da utilidade de filmes como forma de investigação de aspectos educacionais. Na sua visão, os filmes, pelo menos uma vasta porção deles, são dedicados para o entretenimento de massas, não para fins educacionais, embora todos eles incorporem pelo menos uma mensagem específica.

Os filmes em geral são primordialmente produzidos para provocar respostas emocionais, como riso, raiva, medo e terror, choro, ódio, enfim, provocar sensações diversas, tudo para potencializar os sentimentos do espectador. Em resumo, eles são produzidos para causar prazeres artificiais ou outras reações que não de indiferença, e não são feitos para serem veículos de análises sociológicas consistentes sobre ética, liderança, comportamentos organizacionais ou estilos de administração. Portanto, a indústria do entretenimento não tem a finalidade de provocar reflexões ou pensamentos. Significa inferir que, passadas as horas de projeção do filme, o espectador pode isentar-se de qualquer sensação de culpa se não 
conseguir apreender quase nada, apenas se divertir. Em termos práticos, sob a ótica do entretenimento, os filmes comerciais servem para serem vistos por espectadores sedentos de emoção, munidos de pipoca e refrigerante.

A utilização de filmes denominados comerciais nos workshops que envolvem motivação, liderança, coaching, sensibilização, ou habilidades gerenciais sempre foi objeto de conhecidos palestrantes haja vista que nessas sessões de treinamento e desenvolvimento de pessoas certas cenas potencializam situações que se assemelham com uma situação real em uma empresa. O filme permite o "gancho" para o instrutor fazer uma analogia entre o personagem ou situação do filme com a prática na empresa. Mesmo assim, Stilman II alerta que a rotina do dia a dia na organização, as situações racionais, geralmente permeadas por atividades rotineiras enfadonhas e repletas de aborrecimentos, são ignoradas pelos cineastas porque não é o que o público gosta e quer ver, e, que não evocariam sentimentos e sensações da audiência.

Por isso, ao invés de análises sistemáticas da complexa máquina administrativa, são as pessoas e seus complicados relacionamentos humanos que os roteiristas procuram focar porque obviamente isso atrai ampla atenção do público (p. 113). Talvez isso explique o sucesso da série "The Office”, que mostra de modo bem humorado a interação entre os diversos colegas de trabalho em uma empresa fictícia, assim como os diversos seriados cinematográficos e "reality shows" adaptados aos ambientes corporativos que mostram a motivação humana rumo ao sucesso gerencial, como é o caso de “O Aprendiz”. A recente utilização do filme “Tropa de Elite” (2007) em treinamento de executivos é um exemplo de situação extrema de "uma realidade imposta ao indivíduo" (de acordo com o diretor do filme), de stress de desenvolvimento de mecanismos de seleção de pessoal, de motivação dos subordinados, ou seja, de ações típicas de executivos de empresas.

As vantagens dos filmes são tornar-se fontes básicas de diálogo entre os gêneros, classes sociais, etnias, como resultado da promoção de um diálogo cultural e de cunho humano; eles podem suplementar os textos básicos de aprendizado em aula. Certamente, os filmes não vão se tornar o motivo central do aprendizado, mas suas imagens podem comunicar de forma muito mais eficaz alguns aspectos que não são fáceis de serem descobertos por qualquer outro meio, como exemplo, através da leitura de um livro. A partir dessa lógica, são os enredos dos livros que são adaptados para os filmes, embora haja uma 
advertência por parte dos críticos de cinema de que grande literatura raramente é traduzida em grande cinema. A recíproca também não é verdadeira: um grande filme dificilmente pode ser transposto para um livro.

Mais recentemente, até os treinadores de alguma modalidade esportiva têm utilizado essa mídia, como mostra um estudo de Jenkins (2005), que menciona o futebol americano como uma das maiores metáforas para exemplificar a liderança. Um exemplo brasileiro ocorreu em dezembro de 2007, com o uso da parte final do filme "Um Domingo Qualquer” por um técnico de futebol de uma tradicional equipe de São Paulo. Tratava-se da última partida do campeonato, cuja vitória evitaria que essa equipe caísse para a segunda divisão do campeonato brasileiro. A situação era muito parecida com a mostrada no próprio filme, em que um técnico de futebol americano faz uma preleção ao seu time, motivando os jogadores a vencer o jogo na "raça”. Mas, os jogadores não seguiram o mesmo roteiro do filme, não mostraram a motivação exigida, a equipe não conseguiu vencer a partida e foi rebaixada para a segunda divisão. Do ponto de vista estratégico, o erro foi de avaliação do potencial do adversário e a dependência de uma combinação de resultados de outras partidas marcadas para o mesmo dia e hora.

Conquanto o uso de filmes para propósitos instrucionais possua muitas limitações intelectuais, como já explicadas, pode-se dizer que eles se constituem na melhor mídia para a exposição de aspectos intangíveis como a emoção. A emoção, colocada em um contexto adequado, é um poderoso componente dos filmes e possibilita o espectador compreender os aspectos mais profundos do comportamento humano e também perceber, por alguns instantes, além da realidade consciente da vida. Tanto "A Sociedade dos Poetas Mortos" quanto “O Preço do Desafio” (1988), "Meu Mestre, Minha Vida” (1989) e “O Triunfo” (2006) demonstram como professores inspiram com sucesso os estudantes de mundos muito diferentes. Esses filmes salientam o quanto a inspiração pode mudar as vidas das pessoas, embora isso não seja um fenômeno necessariamente factual, observável ou mensurável. O “Clube do Imperador” inverte o foco, inspirando o espectador.

Embora irrelevante para as finalidades de pesquisa, já que não é possível comprovar por meio de uma análise “objetiva”, os filmes enfatizam que aspectos intangíveis como a emoção, os sentimentos, a intuição, as sensações são críticos no relacionamento professor-aluno. Filmes, diferentemente de outros métodos de aprendizado, ilustram o que é 
possível em todas as pessoas, isto é, potencializam uma visão e motivam pessoas a perseguir algo muito mais do que o planejado, o concebido ou o esperado. Talvez esteja aqui a principal razão para a utilização de filmes de longa metragem para fins educacionais.

Por outro lado, o uso de filmes de curta metragem e de documentários específicos vem de longa data, principalmente no Brasil. Alguns pesquisadores, entre eles, Catelli (2003) e Iumatti e Battaglia (2000), desenvolveram estudos a respeito da estreita relação entre cinema e educação no Brasil. Para Catelli (2003), a relação entre cinema e educação data desde as primeiras décadas do século XX, ocasião em que os educadores combatiam o que eles chamavam de "cinema mercantil” e propunham a criação do cinema educativo que poderia trazer benefícios pedagógicos aos alunos ao mostrar de forma real diversos aspectos da natureza e da geografia do Brasil, o que configurava o documentário.

Ainda de acordo com Catelli (2003), o uso do cinema como instrumento pedagógico, doutrinário ou de propaganda era comum, no início do século XX, em vários países do mundo, independentemente da ideologia vigente nesses países. Assim, Estados Unidos, Inglaterra, Alemanha, França, União Soviética e Canadá estão entre os países que difundiram este uso para as imagens cinematográficas. Na União Soviética, o cinema educativo, o cinema científico e de animação ocupavam lugar privilegiado no programa cultural. Não é de estranhar, portanto, que o filme de curta metragem ou documentário continue até hoje sendo utilizado para fins educacionais, ainda mais porque os recursos tecnológicos têm sido amplificados, provocando muito mais emoção, o que pode impulsionar o aprendizado.

\section{O PROFESSOR E OS MÉTODOS DE ENSINO-APRENDIZAGEM}

Ser professor significa aprender com os seus alunos. Phelps (2004) diz que essa frase faz lembrar a relação íntima entre ensinar e aprender. Quer dizer, ser professor é ser um aprendedor. Para se conectar com os alunos, é preciso encontrar formas de aprender com eles. É uma relação de aprendizado recíproco, sendo que uma das formas de aprender com o aluno é obter dele o input: outra forma de aprender com eles é convidá-los a avaliar suas experiências de aprendizado. Todas essas formas de aprender a partir dos alunos envolvem sempre o feedback recíproco entre professor e aluno. 
Andrade e Amboni (2006) pregam que o professor tem que possuir domínio do conteúdo, da comunicação e do relacionamento como elementos-chave da aprendizagem. Ao avaliar o aluno, o professor verifica o domínio do conteúdo, geralmente de uma forma quantitativa, o nível de conhecimento sobre o que o professor ensina. Estudos de Aluko (1994), porém, mostram que o ato de ensinar está muito além do que somente transmitir conhecimento para o estudante. A competência do professor como um bom comunicador, tanto verbalmente quanto na habilidade em escrever, é primordial na cultura ocidental; na atividade de ensino-aprendizagem, essas habilidades de comunicação são cruciais, e o não preenchimento desse requisito é apontado como o fator preponderante de fracasso profissional. Por outro lado, a História está repleta de exemplos em que grandes gênios da ciência, embora brilhantes intelectuais, fracassaram como professores por não possuírem essa habilidade de relacionamento, o que bloquearam o aprendizado dos estudantes.

Interessante reflexão sobre a missão do professor é feita por Lumpkin (2007), que diz:

\begin{abstract}
Os professores são encarregados de educar e, de forma significativa, em moldar as vidas de líderes e cidadãos do futuro. Como depositários dessa temerosa confiança pública, espera-se que os professores vivam de acordo com princípios que são regras universais de conduta moral que guiam ações, intenções e motivos. Professores com princípios modelam condutas que se encaixam nos comportamentos morais inerentemente corretos.
\end{abstract}

Ainda de acordo com Lumpkin (2007), o cerne do caráter dos professores é a aderência a um código de valores morais, ou integridade. Professores éticos em seus relacionamentos com os alunos baseiam suas ações e palavras em valores morais; tais professores demonstram respeito por todos os estudantes, sem distinção de gênero, etnia, classe social, orientação sexual, religião, nacionalidade, crença política, ou outros atributos pessoais. Mais ainda, professores éticos fazem com que todos os estudantes tenham como princípio a civilidade no relacionamento interpessoal não só em sala de aula quanto fora de aula. De acordo com a autora, considerando-se como base a integridade, o ato de ensinar é uma profissão ética que requer a interação de seis comportamentos fundamentais: (1) preocupação e respeito pelo aluno; (2) estabelecimento de altos padrões; (3) provimento de experiências de aprendizado intelectualmente desafiadoras; (4) capacidade de organizar e 
cuidar das turmas para facilitar o aprendizado; (5) estabelecimento de uma cultura de aula centrada no aluno; e (6) reflexão contínua e amplificação do ato de ensinar.

\section{A RELAÇÃO PROFESSOR-ALUNO}

A relação do professor com o aluno é fundamental em todos os níveis e modalidades de ensino/aprendizagem. Por meio dessa relação, que deve resultar em uma interação completa, o aluno pode ser motivado a construir o seu conhecimento com a ajuda do professor. Vygotsky (1896-1934) pregava que essa relação deveria ser de cooperação, de respeito e de crescimento. O estudante deveria ser considerado um sujeito interativo e ativo no seu processo de construção de conhecimento, assumindo o educador um papel fundamental nesse processo, agindo como um indivíduo mais experiente.

De acordo com o staff do Center of Teaching and Learning (CTL), da Universidade da Carolina do Norte (2001), os professores devem tratar todos os estudantes com cortesia e dignidade. A educação superior está comprometida com o princípio em que o debate intelectual deve ocorrer livre de referência às características pessoais dos envolvidos, e se um estudante ficar incomodado, humilhado ou depreciado por algo que um professor fez ou deixou de fazer, a educação terá sido prestado de forma deficiente.

A relação entre o professor e o aluno, ou entre o educador e o educando, para ser produtiva, precisa refletir certas atitudes e compromissos de cada lado. É consenso entre os educadores que, especificamente, três elementos devem fazer parte dessa relação: a) o aluno deve respeitar seu professor e tê-lo em elevada estima para que os seus ensinamentos sejam aceitos. Seria como uma relação entre um médico e seu paciente, ou do seu advogado com o cliente; b) o estudante precisa confiar na boa-fé do professor, que este visa os melhores interesses do aluno; c) o estudante tem que compromissar-se a seguir as instruções com a maior disciplina possível porque só assim pode o efeito intencionado ser alcançado.

O professor tem também três níveis de responsabilidade para com os estudantes em relação ao ensinamento: a) ele precisa conhecer os estudantes individualmente, pois, à medida que a familiaridade dos professores para com os problemas dos alunos cresce, o aprendizado é maior. b) ele precisa expressar afeição para com seus 
alunos. É essa afeição que elimina a tendência natural dos alunos de resistir ao aprendizado. A medida dessa afeição é refletida na preocupação do professor pelo equilíbrio das personalidades dos seus alunos, de modo que eles se sintam seguros em utilizar seus talentos e explorar integralmente o potencial que dispõem. c) ele precisa tomar tempo para refletir sobre o progresso dos estudantes, refinando e ajustando sua visão de como melhor influenciá-los para uma mudança positiva.

Glasser (1969) já havia enfatizado que uma relação calorosa de um professor com os estudantes está correlacionada com o sucesso escolar. Mais tarde, Glasser (1993) mostrou que é imprescindível que, ao permitirem aos alunos fazerem-se conhecidos e fazerem com que eles gostem do seu mestre, os professores terão conduzido os estudantes a um maior esforço, conseqüentemente, aumentando as oportunidades de sucesso. Muitos outros autores, entre eles, Halawah (2006), mostram que a interação informal entre estudante e corpo docente pode positivamente afetar o avanço intelectual e pessoal dos estudantes.

Por outro lado, é necessário que os professores mantenham certa distância a ponto de evitar que sejam vistos como um amigo, já que, em muitas ocasiões, eles vão precisar avaliar o trabalho e atribuir notas a esses alunos, atividades que se tornarão complicadas se não houver fronteiras éticas impostas por este tipo de relacionamento. Os professores devem esforçar-se por manter essa distância ideal para evitar situações de conflito de interesse e acolher quaisquer obrigações inadequadas com os alunos; por outro lado, essas relações devem ser suficientemente próximas para ajudar os professores de modo amigável e a fazerem-se compreendidos, e cautelosamente distantes para não serem confundidas com intimidade.

De acordo com estudos de Hopkins (1993), estudantes de sucesso classificaram seus professores primeiro como amigos, em segundo lugar como auxiliadores, e em terceiro, como professores. Werner (1990) mostrou que os professores que "promovem suporte emocional, premiam a competência e promovem auto-estima” são considerados como os fatores que diminuem a vulnerabilidade do alto risco dos estudantes em resposta a eventos estressantes da vida. Manter, portanto, a fronteira entre ser amigo e a distância ideal é questão de sabedoria para um professor.

Ao procurar ficar cautelosamente distante dos alunos, o professor deve possuir um senso de discernimento para evitar ser visto como autoritário. O fato de os 
estudantes já verem o professor como um indivíduo investido de autoridade deve ser bem ponderado pelo professor, pois o exercício dessa autoridade de modo exagerado pode causar danos a um relacionamento harmonioso com os alunos; todavia, o mau uso dessa autoridade pode ser muito mais danoso ainda. Ser rígido demais é tão ruim quanto ser flexível demais; o professor, portanto, deve saber calibrar a dose de rigidez e flexibilidade.

Como o exposto, a relação entre professor e aluno pode ser definida como de confiança. Confiança, de acordo com o Dicionário Webster’s (1991), é uma expressão do século XIII, provavelmente de origem escandinava, que diz respeito a uma crença forte na honestidade, integridade, justiça, etc, de uma outra pessoa ou coisa; ou uma obrigação ou responsabilidade imposta a uma pessoa em quem a autoridade é posta (p. 1268).

McLeod (2006) explica que a confiança é tão importante quanto perigosa. É importante porque nos permite construir relacionamentos com outros e depender deles - em questões como amor, conselho, ajuda -, especialmente quando sabemos que nenhuma força externa (por exemplo, a lei) obriga-nos a dispor de tais coisas. A confiança sempre envolve o risco de que a pessoa em quem se confia não vai desapontar a pessoa que deposita essa confiança. O risco que se corre enquanto se está confiando em alguém é a perda de coisas que se confia a outros, incluindo a auto-estima, a qual pode ser abalada pela traição da confiança.

Um outro conceito de confiança é fornecido por Fukuyama (1996, p. 41):

[...] confiança é a expectativa que nasce no seio de uma comunidade de comportamento estável, honesto e cooperativo, baseado em normas compartilhadas pelos membros dessa comunidade. Essas normas podem ser sobre questões de "valor" profundo, como na natureza de Deus ou da justiça, mas também compreendem normas seculares, como padrões profissionais e códigos de comportamento. Isto é, confiamos em que um médico não nos causará mal deliberadamente porque esperamos que ele respeite o juramento hipocrático e os padrões da profissão médica.

Igualmente, mesmo que não haja nenhum juramento, espera-se que o professor mostre, no mínimo, essa relação de confiança com o aluno para a consecução dos objetivos educacionais. Mais adiante, Fukuyama (p. 41) cita que: 
[...] o capital social é uma capacidade que decorre da prevalência de confiança numa sociedade ou em certas partes dessa sociedade. (A confiança) pode ser incorporada no menor e no mais fundamental grupo social (a família), assim como no maior de todos os grupos (a nação), e em todos os demais grupos intermediários. [.] a confiança não é necessária à cooperação; o auto-interesse esclarecido, juntamente com mecanismos legais como contratos, pode compensar a ausência de confiança e permitir que estranhos criem em conjunto uma organização que trabalhará em prol de um propósito comum.

Para Covey (2008, p. 5), confiança:

[...] significa ter certeza de que a pessoa não esconde nada e é sincera. O oposto da confiança - a desconfiança - é a suspeita sobre sua sinceridade. Quando você confia nas pessoas, você confia em sua integridade e em suas competências. Quando desconfia das pessoas você desconfia de suas intenções e atitudes e de sua integridade, sua agenda, suas competências ou seus antecedentes.

Covey também destaca a diferença entre a alta e a baixa confiança, ao mesmo tempo em que propõe uma fórmula simples que permite ver a confiança como fator tangível e quantificável, sendo esta função da velocidade e do custo. Assim, quando a confiança é alta, a velocidade (da confiança) aumenta e o custo decresce; ao contrário, quando a confiança é baixa, a velocidade diminui e o custo aumenta (p. 5-6). Covey, ainda, parte de um conjunto de pressupostos (p. 25-26): (1) a confiança é tangível, real e quantificável; (2) nada é tão rápido quanto a velocidade da confiança; (3) a confiança é uma função tanto do caráter quanto da competência; (4) a confiança tanto pode ser edificada quanto destruída; (5) embora seja difícil, na maioria dos casos, a confiança perdida pode ser recuperada; (6) a confiança pode ser ensinada e aprendida eficazmente, e pode tornar-se uma vantagem estratégica multiplicadora; (7) não confiar nas pessoas é um risco maior; e (8) a confiança estabelecida com uma pessoa multiplica-se em muitas.

Fazendo uma analogia com a terminologia empregada no mercado monetário e financeiro, a relação de confiança entre professor e aluno pode ser comparada a uma relação fiduciária. A expressão fiduciária é proveniente da palavra latina fiducia, que significa confiança, que acabou tornando-se útil como terminologia para a moeda e para o mercado financeiro. Assim, o valor do papel-moeda (como, por exemplo, a inscrição do valor no papel representando a cédula de determinado montante) vale fiduciariamente o valor escrito porque o público tem a confiança no emissor (o Banco Central) que concede o valor fiduciário à moeda; em suma, vale aquilo estampado na cédula. 
A relação fiduciária no mercado financeiro ocorre quando um profissional age em nome de outrem, que tem a obrigação de administrar determinada conta com escrúpulo e correção, mesmo que o cliente não esteja monitorando ou fiscalizando a atuação do administrador (MONOBE; BENEDICTO; CALIL, 2006, p. 325-359). Feldman-Summers (1989) apud Plaut (1993) define um relacionamento fiduciário como "uma relação especial na qual uma pessoa aceita a confiança de uma outra para agir nos melhores interesses desta última”, e Jorgenson (1992) apud Plaut (1993) acrescenta que "em tais relacionamentos, as partes não são tratadas em termos iguais. O fiduciário precisa agir com a mais elevada boa-fé e somente para o benefício da parte dependente”.

Feldman-Summers segue explicando que "não há dúvida que médicos, psiquiatras, conselheiros e advogados são fiduciários.” Pode-se argumentar que outros profissionais, como os professores, devem ser incluídos no rol de fiduciários, já que os alunos freqüentemente depositam confiança em seus professores de uma maneira similar à que é observada nas relações entre terapeuta e cliente, especialmente quando o professor é procurado para dar orientação e assistência individual. O professor é fiduciário também na avaliação do aluno: mesmo com as melhores intenções, ele pode cometer um erro involuntário, o que é desculpável. Porém, se esse erro é voluntário, existe uma quebra de confiança na relação professor-aluno.

Rutter (1989) lembra que:

[...] sempre existe uma zona proibida na relação entre doutor e paciente, terapeuta e cliente, clérigo e fiel, advogado e cliente, professor e aluno. Todas essas profissões embutem uma confiança especial que previne o abuso dos elementos dependentes vistos ou não vistos que inevitavelmente se desenvolvem.

Devido ao maior poder do profissional, o cliente é incapaz de dar um verdadeiro consentimento, e, portanto, é responsabilidade da pessoa na posição de mais poder controlar a fronteira necessária entre as duas partes. A extensão dessa posição no meio acadêmico foi posta pelo Diretor da Universidade de Harvard, afirmando que:

[...] tais relacionamentos podem ter um efeito de minar a atmosfera de confiança na qual o processo educacional depende. Implícito na idéia de profissionalismo está o reconhecimento por aqueles em posições de autoridade que em seus relacionamentos com estudantes sempre há um elemento de poder. É incumbência daqueles com autoridade não abusar, nem parecer abusar, do poder com o qual estão investidos. 
Levinson (1978) menciona a relação de mentor na supervisão direta do aprendizado do estudante. De acordo com ele, o mentor pode desempenhar diversos papéis: como professor ele é responsável por ampliar as habilidades dos estudantes e o desenvolvimento intelectual. Como patrocinador, o professor deve facilitar a entrada do estudante no mercado e no desenvolvimento na profissão. Como guia, o professor inicia o estudante no mundo social e ocupacional e o conscientiza com seus valores, costumes, recursos e galeria de personagens. Como modelo, o professor serve como aquele em que o estudante se espelha. O professor também serve como um conselheiro em tempos de stress. Mas, sobretudo, o papel do mentor é também avaliar o desempenho do estudante.

\section{LIÇÕES DO FILME}

O enredo de "O Clube do Imperador" gira em torno de William Hundert, que narra em flashbacks seus tempos como professor, depois de lecionar por 34 anos na St. Benedict School, uma tradicional instituição privada de ensino, exclusiva para adolescentes do gênero masculino na Costa Leste dos EUA. A escola é o palco onde o professor cita lições de moral para serem aprendidas por meio do estudo da Antiguidade.

O professor Hundert é metódico, gosta de dizer aos seus alunos que “o caráter de um homem é o seu destino", e chama à responsabilidade de todos para viver uma vida ordeira, correta e escrupulosa. Nem sua vida particular escapa aos rigores de sua própria ética: embora apaixonado por uma colega casada, ele evita qualquer sinal explícito de envolvimento emocional com ela até o instante em que esta se separa, depois de passar algum tempo em uma universidade européia junto com o então marido.

O sugestivo título do filme pressupõe que apenas um pequeno número de estudantes da classe participará da competição final para se conhecer o vencedor que, por sua vez, deve ser coroado Julius Caesar, o Imperador de Roma. Antes, porém, todos os alunos terão que mostrar que conhecem fatos históricos a respeito do Império Romano em uma seqüência de provas escritas. Essa etapa da avaliação mostra dois aspectos do conceito de confiança na relação professor-aluno: o aluno tem que mostrar o domínio sobre o tema 
em questão sem trapacear, e o professor deve corrigir com isenção e atribuir notas sem qualquer viés pessoal.

Embora seja ficção, em nenhum momento o enredo se mostra inverossímil, não havendo necessidade da ficção criar a sua própria verossimilhança, como acontece na grande maioria dos filmes comerciais de longa metragem. Neste tipo de filme, quanto maior a verossimilhança, maior é a credibilidade no enredo do filme. A relação do professor Hundert com Martin Blythe é o ponto principal do filme sob o ponto de vista da relação professoraluno. Essa relação aparece no início quando Martin Blythe é solicitado a ler a referência a Shukrut Nahunte, soberano de Elam, podendo-se prever o que virá pela frente. Fred Masoudi, porém, é o primeiro aluno a merecer uma sutil admoestação, ao ser flagrado passando por cima da grama, ocasião em que o professor Hundert se aproveita para envolvêlo em um incidente crítico de aprendizagem - não um "olha onde pisa”, como faria um simples professor, mas “siga o caminho”, como faz um educador. Sedgewick Bell é um aluno retardatário.

Outra situação de relacionamento professor-aluno ocorre quando o professor é desafiado a rebater a bola de beisebol, atingindo o vidro do automóvel do diretor da instituição, um outro incidente crítico que representa ao mesmo tempo a fuga à responsabilidade e o desafio ao establishment acadêmico. Ao abandonar apressadamente o local do incidente e juntar-se aos estudantes envolvidos no episódio, o professor leva os alunos a um involuntário pacto de silêncio e cumplicidade, e, de certo modo, a pensarem (entre eles) que "ele é um dos nossos”, apesar de toda a sisudez. O evento não contribui, porém, para macular a relação professor-aluno.

A transgressão às regras é liderada por Sedgewick Bell, ocasião em que os alunos fazem uma incursão para o outro lado do lago, onde se encontram algumas alunas da St. Mary, em atitude de possível quebra de regras daquela instituição. No momento seguinte, o professor Hundert aparece repreendendo e lembrando os internos de que a filosofia da St. Benedict é de confiança mútua e que o castigo aplicado seria uma forma de punir essa quebra de confiança. O que fica implícito na atitude do professor é o pleno exercício da autoridade ao exigir o cumprimento das regras da escola, o que reflete seu poder de exercer o papel de disciplinador e a condição de educador. Como responsável pela preservação da 
imagem da instituição, o professor Hundert não abdica de seus preceitos morais, mesmo em um evento aparentemente de pouca importância.

Poder-se-ia pensar na questão do reconhecimento da importância da identificação que os liderados têm para com o líder, pela má influência que Sedgewick Bell começa a ter nos colegas. Temeroso que o aluno prossiga na violação das regras de boa conduta e desejoso de exercer a função de mentor, o professor Hundert decide visitar o pai de Sedgewick Bell, senador dos Estados Unidos. A acolhida é ambígua, ora está na arrogante oferta de um charuto ou na de um revólver de valor histórico, até o ponto em que o senador pergunta qual o valor do que o professor Hundert está ensinando. É o momento do confronto de duas pessoas com visões diferentes sobre um mesmo tema. Para um educador valor é moldar o caráter, é tornar os alunos cidadãos, por meio do estudo da história da civilização ocidental; para o político é aquilo que mais tarde vai lembrar ao filho, pelo telefone ("você sabe quanto estou pagando pela sua educação?”), é uma mercadoria que se compra. A situação torna-se crítica quando ato seguinte o professor, na condição de mentor, diz querer moldar o caráter de Sedgewick Bell, idéia que é rejeitada pelo senador que afirma que, como pai, é dele essa atribuição. Seria até lógico o argumento do senador, não fosse a equivocada interpretação que este tem de educação e de mentoring, aliás, como a maioria dos políticos. O professor Hundert se conscientiza que o senador entende a educação como custo, e como é ele quem paga a escola para fugir da responsabilidade da participação, julga que a função do professor é apenas repassar informações históricas, sem preocupação com a formação de caráter. O senador não é só um pai distante, é um pai equivocado e descompromissado com a educação. Curioso é que vinte e cinco anos depois, Sedgewick Bell faz um discurso vazio sobre educação nos mesmos moldes que o pai senador faria se estivesse em campanha.

Outro problema é ensinar ética e caráter, o que depende do aluno, seu background familiar e atitude. Na crença popular, caráter é de berço, o que não deixa de ser parcialmente correto, embora incompleto. Como imaginar que Sedgewick Bell possa mudar? Será que o professor Hundert acredita que pode mudar Sedgewick Bell porque ele declama Brutus sem muita convicção? Ou será que o hábito faz o monge e Sedgewick Bell vai incorporar na vida o papel de Brutus perante alguém que, como César, deposita a confiança? É acreditando que pode evitar que Sedgewick Bell encarne Brutus e que o poder da toga possa fazer a transição da infância para a fase adulta, o professor sacrifica seu senso ético ao 
alterar a pontuação em favor deste aluno na fase semifinal da competição, para que este seja um dos três finalistas.

O que parece ter sido a decisão certa, o professor Hundert só descobre ter sido o oposto quando ele próprio descobre a “cola” na final. Do ponto de vista da confiança, é tarde demais, Brutus já está encarnado em Sedgewick Bell. Brutus, que traiu a confiança, não pode tornar-se Julius Caesar. Entendendo que não é tarde para a punição, o professor vale-se de um estratagema que é uma forma sutil de fazer justiça com as próprias mãos. Ao avistar Martin Blythe, sozinho e inconsolável debaixo de uma árvore no campus, o professor Hundert entende a extensão de sua decisão. Mais tarde, o professor acredita que a segunda chance, solicitada por Sedgewick Bell, em forma de chantagem (volumosa doação à escola), seria a dupla redenção, pois este conseguiria reverter a derrota de vinte e cinco anos atrás, enquanto o professor (caso o pretendente ganhasse a competição limpamente) se sentiria aliviado pela ajuda inútil que havia dado a Sedgewick Bell anteriormente e se redimiria da injustiça cometida com Martin Blythe. O espectador de boa-fé também é enganado por essa impressão.

Nessa segunda chance, o caráter novamente acaba prevalecendo. Aliás, Sedgewick Bell se supera: ele aperfeiçoa o engodo, desta vez, com toda a certeza de que não será descoberto. Talvez a maior frustração do professor Hundert é ver que sua máxima - “o caráter do homem é seu destino” - é desprezada exatamente no clímax da competição, e justamente pelo aluno por quem ele havia negligenciado o conceito de confiança. Alguns momentos de dúvida ficam no ar, como por exemplo, a devolução do livro que o professor havia dado vinte e cinco anos antes, para que Sedgewick Bell se preparasse para as provas. Ao devolver o livro, o ex-aluno parece ter incorporado conhecimento e passa a falsa impressão de ter aprendido a noção de caráter. Fato consumado, o professor Hundert confessa o seu fracasso para com Sedgewick Bell, não como professor (ensinando a História da Civilização Ocidental), mas como educador (incapaz de tornar verdade o seu lema “o caráter de um homem é seu destino”). Como professor ético, o professor Hundert deve ter tido seus momentos de culpa, não Sedgewick Bell, para quem caráter não interessa, ou, de acordo com suas próprias palavras, “não está se lixando”.

A conclusão que se pode tirar é que o professor Hundert aprendeu a lição por ter violado o princípio fiduciário de ser justo, embora só ele tivesse condições de saber. 
Sedgewick Bell não aprendeu nada; inseguro e, sobretudo, desonesto, a “cola” se tornou uma muleta ao qual ele recorreu sem sucesso para preservar seu relativismo moral. Com uma diferença: os métodos de violação da ética, da honestidade e da confiança são aperfeiçoados, e, assim, a técnica da "cola” é adaptada aos ditames da evolução da tecnologia. O fato de ser um empreendedor de sucesso e a desmesurada ambição política torna qualquer interpretação redundante. Sedgewick Bell, no final, quer tornar-se igual ao falecido pai ao anunciar a candidatura ao Senado. Querendo ganhar para tornar-se Julius Caeser, ele acabou como Shutruk Nahunte, o destruidor de Sipar, de grande ambição, mas sem nenhuma contribuição, e, portanto, sem valor. É a saga de um reles político.

O professor Hundert, porém, mostra ser um professor ético e transparente quando procura Martin Blythe para contar que havia favorecido Sedgewick Bell, para que este fosse um dos finalistas, o que só ele sabia até então. A homenagem que os ex-alunos prestam sem a presença de Sedgewick Bell, ocupado demais com a campanha eleitoral com ênfase na educação - é um momento de glória e uma recompensa para um professor dedicado: é a demonstração que seus alunos aprenderam. Sua máxima foi enfim reconhecida. Cabe a Martin Blythe, porém, a grande demonstração de aprendizado, evidenciada na matrícula de seu filho na St. Benedict, agora uma escola mista, para moças e rapazes. Como era de se esperar, Sedgewick Bell não matricula seu filho na St. Benedict, talvez porque este descobriu a farsa que é o seu pai, ao ouvir involuntariamente a conversa na toalete. Ou talvez porque existe certo temor de que o professor Hundert ou qualquer outro vá “moldar o caráter” do filho. O professor Hundert também mostra ter entendido que uma boa relação professoraluno é produtiva quando o aprendizado é recíproco e volta a lecionar na escola. Assim, o professor reabre o livro de sua vida, que, no principio, dizia ter fechado. A promoção a Diretor, que lhe fora negada anteriormente, não interessa porque em algum momento o professor Hundert deve ter compreendido que ser educador é o máximo da carreira acadêmica, não a de Diretor (Headmaster) da St. Benedict, que representa o ápice de uma carreira burocrática, embora de amplo prestígio.

Longe de ter um final feliz, o filme remete o espectador a um momento de reflexão: a ética compensa. O final feliz, portanto, fica a cargo do espectador. Em um dos trechos iniciais do filme, um adolescente - Martin Blythe - é solicitado a ler a inscrição na porta; no final, um rapaz que chega atrasado é apresentando como filho de Martin Blythe também chamado Martin Blythe - e, como o pai, é solicitado a ler a mesma inscrição sobre 
Shutruk Nahunte. E, assim, a história recomeça com o mesmo professor. A esperança fica no ar: quem sabe, este jovem Martin Blythe possa vir a ser Julius Cesar, com um intervalo de duas gerações. O espectador respira essa esperança e deve acreditar que é o relacionamento professor-aluno o verdadeiro Julius Caesar.

\section{CONSIDERAÇÕES FINAIS}

O ato de ensinar, levado a efeito como uma profissão ética, deve embutir o conceito de integridade no relacionamento entre professor e aluno. Muitas regras, escritas e não escritas, que se referem a esse relacionamento entre professor e aluno, estão no âmbito do senso comum. De forma simples, a integridade serve como o elo de aprendizado entre professores e alunos. O professor ético procura comprometer-se em criar e organizar um ambiente propício ao aprendizado, pondo em relevo a reflexão.

É repetida à exaustão a crença que, à medida que professores éticos mostram o quanto eles se preocupam com seus estudantes, estes nutrem reciprocamente confiança e respeito. Estudos de vários pesquisadores mostram que os estudantes respondem positivamente aos padrões elevados estabelecidos pelo professor, que exigem propostas de aprendizado intelectualmente desafiadoras. Essa troca de experiências, porém, só é possível dentro de um relacionamento professor-aluno de confiança mútua.

Diversas passagens do filme "O Clube do Imperador" mostram que o relacionamento do professor Hundert com os seus alunos leva sempre a um aprendizado elevado cujo clímax é a vitória do mais brilhante contendor, que é coroado Julius Caesar. Como é típico em uma relação fiduciária, as regras estabelecidas são claras, transparentes. Mas, ambos - o professor Hundert e Sedgewick Bell - acabam violando o conceito de confiança, aquele na fase de classificação, quando exerce o poder fiduciário na escolha de um em detrimento de outro competidor, e Sedgewick Bell pela forma como tentou vencer a competição. De diferente apenas é que o professor Hundert se redime quando torna transparente a injustiça cometida (que a “vítima” perdoa ao matricular seu filho na escola), o que para qualquer outro professor poderia ter sido mantido em segredo. Curioso é que o excluído na competição (Martin Blythe) obriga o espectador a se colocar no lugar de 
Amílcar Barca, ao seja, do lado do "perdedor". Só que existe uma diferença: este se torna o centro da história, ao contrário daquele que é esquecido.

O professor Hundert é firme, disciplinador, sem ser autoritário. Sabe usar de sua autoridade, utiliza o timing exato em assumir um papel ou outro. Nos Estados Unidos, não se admite a "cola" (cheating), pois representa quebra de confiança e violação do contrato educacional. No sentido fiduciário, a “cola” é uma das maiores violações do conceito de confiança. Pesquisas indicam que a “cola” é uma prática enraizada na cultura escolar norteamericana, mesmo que haja por parte das instituições de ensino uma cuidadosa prevenção, além de severas punições para os infratores, incluindo a expulsão. Do ponto de vista do estudante, a “cola” é um instrumento que o aluno utiliza se o professor negligencia as práticas de avaliação, quando as classes são grandes, as condições são propícias e os riscos são mínimos. O risco que Sedgewick Bell assume é apenas moral, o que não é grande coisa para ele. Na segunda chance, os riscos são aparentemente menores ainda, já que o avanço da tecnologia das comunicações permite a Sedgewick Bell dispor de um ponto eletrônico eficiente e difícil de ser percebido.

Como foi dito, a relação professor-aluno é fundamental em todos os níveis e modalidades de ensino/aprendizagem. Além disso, um ambiente caracterizado por confiança mútua e respeito conduz a um maior aprendizado à medida que os estudantes entendem que seus mentores têm uma ambiciosa, embora honesta, avaliação de suas habilidades e desempenhos. Também, os professores éticos estabelecem altos padrões por esperarem mais de seus alunos, sendo o caráter o maior deles - este é um grande desafio de um educador. Desafio maior, porém, é apresentar esse enredo em um filme de longa metragem, em que a preocupação principal é o entretenimento das massas, sem ser piegas ou cair no lugar comum. Porém, os recursos visuais, aliados ao desempenho teatral e à emoção, garantem que um mínimo de consciência é possível de se obter. O filme comercial pode ser considerado uma mentira bem contada, mas convence o espectador e, por isso, pode ser eficaz como apoio aos propósitos educacionais. 


\section{REFERÊNCIAS}

ALUKO, S.O. The impact of student-faculty informal interpersonal relationships on intellectual and personal development in the University of Lagos. 1994. Tese (Doutorado) - University of Northern Texas, Arizona, 1994.

ANDRADE, R. O. B.; AMBONI, N. Teoria da administração: os desafios do professor frente às novas diretrizes curriculares. São Paulo: M.Books do Brasil Editora, 2006.

CATELLI, R. E. Cinema e Educação em John Grierson. Mnemocine, v. 1, p. 1-3, 2003. Disponível em: $<$ http//www.mnemocine.com.br>. Acesso em 26 fev. 2008.

CENTER OF TEACHING AND LEARNING (CTL). The relationship between student and teacher. University of North Carolina, 2001.

Disponível em: <http://ctl.unc.edu/hir4.html>. Acesso em: 26 fev. 2008.

COVEY, S. M. R.; MERRILL, R. R. O Poder da confiança. Rio de Janeiro: Elsevier Editora, 2008.

FUKUYAMA, F. Confiança: as virtudes sociais e a criação de prosperidade. Trad. Alberto Lopes. Rio de Janeiro: Rocco, 1996.

GLASSER, W. Schools without failure. New York: Harper \& Row, 1969.

The quality school teacher. New York: Harper Collins 1993.

HALAWAH, I. The impact of student-faculty informal Interpersonal Relationships on Intellectual and Personal Development. In: College Student Journal, Setembro/2006.

IUMATI, A. B.; BATTAGLiA, L. Um Diálogo Possível entre Cinema e Educação. Disponível em: <www.mnenomocine.com.br/ cinema/cri/ sereter_elefante.html >. Acesso em 14 mar. de 2008.

JENKINS, W. The Pitch for a New Leadership Metaphor. Human Resource Planning, Jan. 2005.

LEVINSON, D.J. The seasons of a man’s life. New York: Alfred A. Knopf, 1978.

LUMPKIN, A. Teaching as an ethical profession. Phi Kappa Phi Forum, Summer, 2007. Disponível em: <http:findarticles.com/p/articles/mi_qa4026/is_200707/ai_n19511286>

McLEOD, C. Trust. In: Stanford Encyclopedia of Philosophy, 2006.

MONOBE, T.; BENEDICTO, G. C.; CALIL, J. F. Processo de Controle de Gestão de Investimentos. In: SOUSA, J. E. R., CALIL, J. F.; MONOBE, T. (Orgs.) Estratégia Organizacional.. Campinas: Akadêmica Editora, 2006. 
PHELPS, P. H. Learning from your students. Kappa Delta Pi Record, Summer 2004.

Disponível em: <http://findarticles.com/p/mi_qa4009/is_200407/ai_n9424247>.

PLAUT, S. M. Boundaries Issues in Teacher-Student Relationships. The Journal of Sex and Marital Therapy, n. 19, p. 210-219, 1993.

RUTTER, P. Sex in the forbidden zone. Faucet Crest, 1989.

STILLMAN II, R. J. Exploring films about ethical leadership: can lessons be learned? Public Administration Management, v. 11, n.3, p. 103-305, 2006.

VYGOTSKY, Webster Ninth New Collegiate Dictionary. Disponível em:

www.centrodereferenciaeducacional.com.br/vygotsky.html. Merriam-Webster Inc., 1991.

WERNER, E.E. Protective factors and individual resilience. In: HANDBOOK: of early childhood intervention. Cambridge University Press. New York: 1990. p. 97-116. 